\title{
Los chichas, los lipes y un posible enclave de la cultura de San Pedro de Atacama en la Puna limítrofe argentino-boliviana
}

JORGE FERNÁNDEZ ${ }^{1}$

El magnífico adelanto verificado en el conocimiento arqueológico de la región norte de Chile durante el último decenio, contrasta con la parvedad de información referida a las regiones vecinas, especialmente el sur boliviano y al extremo noroeste argentino. Por este motivo, muchos de los beneficios emergentes de aquellos progresos no pueden ser extendidos a la zona considerada, la que tradicionalmente ha sido asignada al dominio de los aborígenes chichas, lipes y atacamas en momentos coincidentes con la conquista hispánica, de lo que existen comprobaciones escritas. No obstante, las dificultades han sido enormes cada vez que los estudiosos han intentado establecer la modalidad, los momentos y el grado de interpenetración que cada una de esas etnias históricas ha efectuado sobre sus vecinas del territorio actualmente argentino, en particular casabindos, cochinocas, humahuacas, apatamas, churumatas, tomatas, etc. Coadyuva al mantenimiento de esta oscura situación la circunstancia de no existir clase alguna de estudios etnohistóricos referentes a chichas y a lipes - poco más que nombres vacuos, al igual que los antes enunciados-, y al casi absoluto desconocimiento en que permanece la arqueología del sur boliviano en algunos sectores parejamente compartido por la del extremo norte argentino. Los avances de la arqueología boliviana no han sobrepasado el departamento de Cochabamba y, en cuanto a la argentina, hasta ahora no ha procurado interpenetrarla de alguna forma.

El desconocimiento al que aludimos no está referido a lineamientos culturales de detalle acerca de chichas y lipes: ni siquiera conocemos estructuras de primera magnitud, como son la lengua y el hábitat. Así, Boman (1908: 775) asegura que los chichas no tenían lengua propia, sino que hablaban el quechua; Rivet (1924) expresa que hablaban el aymara desde antes de la conquista incaica; Serrano (1947: 86)

1 Consejo Nacional de Investigaciones Científicas y Técnicas, Buenos Aires, ARGENTINA. piensa que su lengua era el aymara, mientras que Willey (1972: 199) dice que "in southern Bolivia the Lipe and Chicha may have been Aymara-speaking like their neighbors to the north". Por el contrario, Ibarra Grasso (1967: 359) discrepa con las opiniones anteriores, negando que la lengua de estos indígenas haya sido originariamente la aymara, sino que la tenían propia. En lo referente al hábitat chicha, las suposiciones difieren igualmente: hay quienes los han limitado al sureste de Bolivia exclusivamente (departamentos de Tarija y parte de Potosí), y quienes, como Vignati (1931), han propiciado la existencia de una cuña étnica que desde Bolivia se habría extendido en territorio argentino hasta la localidad de Casabindo, donde habrían estado en contacto directo con los diaguitas. Finalmente, algunos autores como Serrano difieren en cuanto a la posición espacial asignable a esa cuña chicha, la cual debería desplazarse más hacia el este, en los confines de Tarija. En tal caso, ese divertículo del territorio de los chichas habría correspondido a los churumatas y tomatas, y estaría emplazado en el extremo norte de Salta; sin embargo, Serrano (1947: 66) acepta que hayan existido indígenas chichas en Cochinoca, es decir, en el sector puneño de Argentina. Chichas orejones, churumatas y tomatas habrían sido, pues, algunas de las diferentes parcialidades chichas o afines a ellos que a mediados del siglo XVI habrían poblado territorio actualmente argentino en la región de la cordillera Oriental.

Sabemos por Garcilaso que atacamas, llipis y chichas fueron puestos bajo la tutela incaica por el inca Yahuar Huaca, entre 1348 y 1370; el historiador se refiere a las provincias de Caranca, Ullaca, Llipi, Chicha y Ampora, "pobladas por gente valiente y belicosa". El sucesor, inca Viracocha, habría sido quien completó esta consolidación territorial y los sujetó en forma definitiva. Sabemos que estos pueblos permanecieron luego continuamente bajo el dominio incaico, habiendo sido después muchas de sus localidades verdaderos tambos incaicos; es en tal modo como fueron conocidos por los españoles. En 1574 había aborígenes chichas en Talina, Cotagaita, Calcha, 


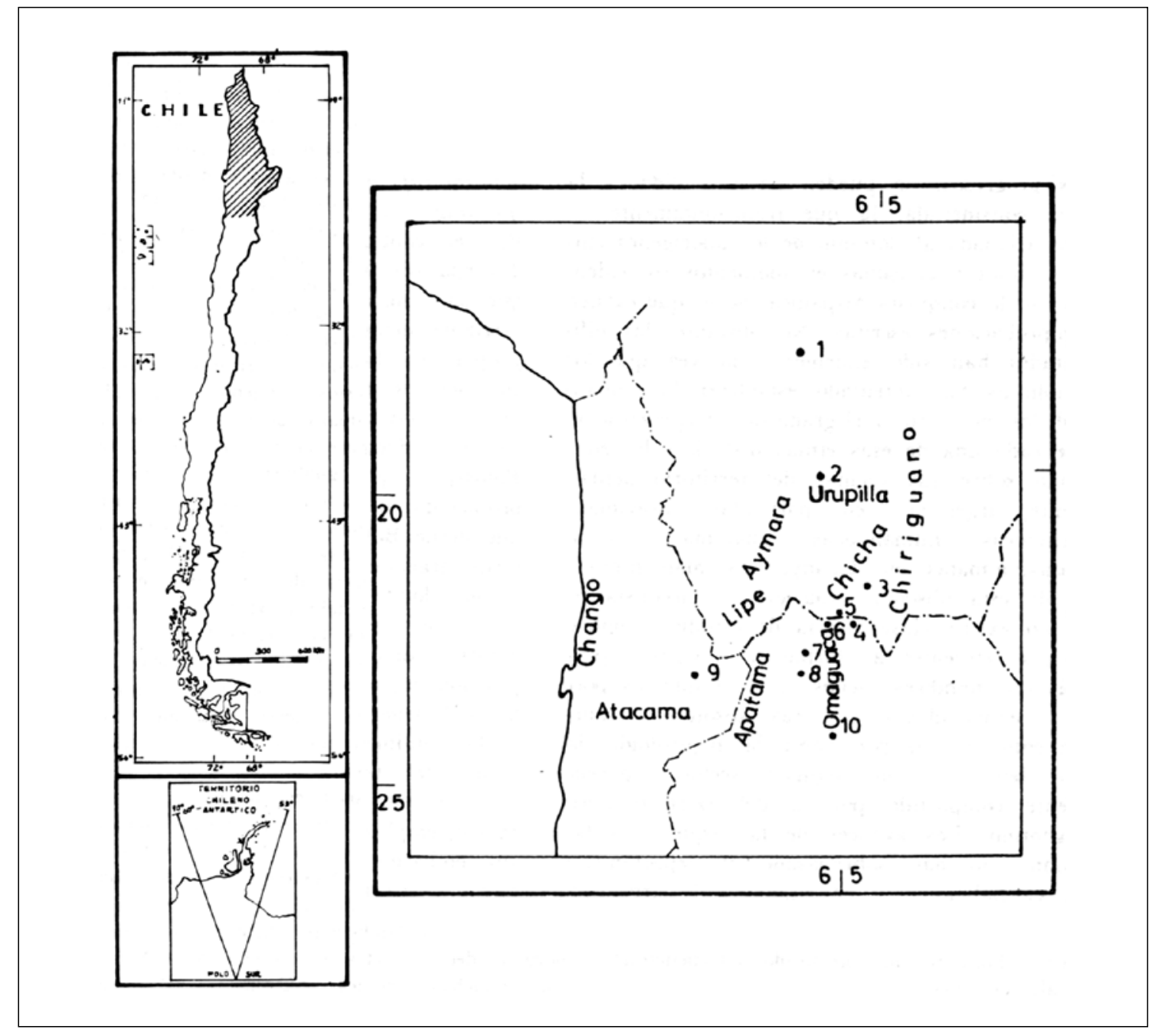

Figura 1. Bosquejo que indica la posición aproximada de algunos pueblos históricos del sur de Bolivia, extremo noroeste de Argentina y de parte del norte de Chile. 1: Cochabamba; 2: Potosí; 3: Tarija; 4: La Quiaca; 5: Calahoyo; 6: Casira; 7: Cochinoca; 8: Casabinbo; 9:

Toconao; 10: Jujuy. La publicación de este mapa ha sido autorizada por la Dirección de Fronteras y Límites del Estado en la resolución 290 de diciembre 1 de 1978, en conformidad al artículo 3 de la Ley 16562.

todos perfectamente identificables ahora. Gracias a los datos de Matienzo, conocemos el modo en que estos establecimientos se encadenaban a distancias de cinco a seis leguas, conformando una especie de rosario sobre la ruta incaica hacia Chile y Tucumán. Al sur de la ciudad de Potosí existían pueblos diferentes a los chichas que marcaban el extremo norte de sus dominios; estos indígenas eran los yamparaes y huruquillas. El primer pueblo de los chichas, viniendo desde el norte, era Calcha, y el siguiente, Bischacha; así se continuaban hasta Calahoyo (sitio sobre la actual frontera argentino-boliviana, trazada sobre los antiguos términos del Alto Perú y Tucumán, pero que en este sector tiene evidentemente antiquísimas raíces étnicas) y Moreta, dentro ya de territorio argentino. Moreta es, consecuentemente, el último poblado o tambo al que lícitamente se le puede aceptar carácter chicha.

Por el este, en la región próxima a los llanos boscosos del Chaco, se hallaban flanqueados por los temibles chiriguanos, otra entidad perfectamente desconocida pese a lo mucho que de ella nos habla la documentación escrita. Periódicamente, los chiriguanos ascendían a la montaña y se cebaban en los desprevenidos chichas, a quienes durante varios siglos tocó desempeñar función amortiguante, interponiéndose entre las hordas chiriguanas 
y los ricos establecimientos mineros españoles vecinos a Potosí. De los chiriguanos tenemos la imagen correspondiente a un pueblo primitivo de la llanura boscosa, pero ignoramos qué productos del metamorfismo pudieron haberse originado del contacto entre los pueblos así etiquetados, con los de la montaña, donde según las crónicas poblaron repetidamente (Figura 1).

En cuanto a los atacamas, son conocidas las alternativas de la discusión referente a su presencia en la Argentina, discusión que en definitiva no ha dirimido nada y en cambio ha confundido mucho más. Como resultado de intensos trabajos de campo, Boman afirmó en 1908 que el occidente de la actual provincia de Jujuy denotaba la prolongada presencia de la etnía atacameña. Para ello, tomó particular cuidado en la comparación de restos culturales procedentes de Calama (Chile) con los de Casabindo y Sayate, en la punta de Jujuy. En dicho estado de conocimiento permaneció la investigación hasta 1931, año en que Vignati negó terminantemente la existencia de núcleos atacameños en parte alguna de Argentina. Como elemento dirimente, analizó el contenido de diversa documentación histórica, fundamentalmente el itinerario del licenciado Matienzo, fechado en 1566. Este último hace referencia a la presencia de indígenas chichas en puntos donde Boman encontrara restos atacameños. Vignati hace especial hincapié en los de Talina, Calahoyo y Moreta, por lo que en su carta étnica asigna todo el sector a los aborígenes chichas, hasta Casabindo, con exclusión absoluta de cualquier influencia atacameña. Posteriormente, ningún arqueólogo extranjero -salvo Latcham-, o argentino -a excepción de Lafon-, ha vuelto a hacer mención de la presunta vigencia de una cultura "atacameña" en la Puna argentina, sea porque la periodificación de ésta en Chile ya no lo permitía, sea porque los argumentos en apariencia contundentes de Vignati lo desaconsejaban. Desde un punto de vista exclusivamente arqueológico, Bennett y colaboradores (1948) establecieron allí la existencia de un "Complejo de la Puna" (Puna Complex), estructurado sobre elementos de la cultura material que, aunque tal vez de antiguo origen, han sido obtenidos en ruinas de poblados en muchos casos resultantes del reacomodamiento y removilización de tribus dispuestos por las autoridades coloniales para la mejor explotación de los recursos regionales. Más conciliador, Canals Frau (1951, 1955), admite la existencia de comunidades de extracción atacameña, o por lo menos de cultura básicamente atacameña -pero de la cual faltarían elementos caracterizantes-, a las que da el nombre de apatamas o apotamas, citados en los documentos históricos. En cuanto a la posible dispersión de la cultura de San Pedro en el suroeste boliviano, desconocemos si se han hecho intentos desde el punto de vista arqueológico o etnohistórico, pero ya veremos oportunamente que existen pruebas afirmativas al respecto.

Pasando ahora a los lipes, llipis u olipes, la información es todavía más pobre. Para una aproximación a su conocimiento, solamente contamos con un documento seguro: la carta que el factor de Potosí, Juan Lozano Machuca (1885: XXI-XXVIII), escribiera al virrey de Perú el 8 de noviembre de 1581. Uno o dos autores han empleado anteriormente este documento; pero como sus conclusiones, en forma global, no me parecen aceptables y su discusión resultaría inconducente, soslayo su tratamiento.

La información aludida no emana directamente de Lozano Machuca, sino de Pedro Sande, algo así como un agente especial de aquella época, quien "fue a los lipes y estuvo allá cuatro o cinco meses viniendo y entendiendo la tierra". No caben dudas en cuanto a que el motivo principal del envío de este observador a los lipes se debió a la necesidad de contar con datos precisos sobre las numerosas vetas de plata que allí se descubrieron por $1570 \mathrm{y}$, por supuesto, de la calidad y cantidad de indígenas que pudieran ser empleados en su explotación.

Pero ¿qué eran los lipes? Leyendo atentamente esta crónica, a veces surge más bien la impresión de que lo que se intitulan los lipes era mejor un repartimiento, una provincia, una tierra o un término, antes que un conglomerado étnico definido, algo así como en el caso de la "provincia de los charcas" o, simplemente, "los charcas". Uno de sus pueblos extremos, por el norte, era Colcha, lugar perfectamente identificable en el borde sur del salar de Uyuni, a $20^{\circ} 50^{\prime}$ Lat. S y $67^{\circ} 47^{\prime} 30^{\prime \prime}$ Long. O, aproximadamente. Pero el centro de la región estaba más hacia el sureste, donde hoy se emplazan la sierra y el pueblo de Lipez (ahora, San Antonio de Lipez) ${ }^{2}$, a poca distancia y enfrentando el departamento jujeño de Santa Catalina. El corazón de toda esta zona era el cerro Escala y caserío del mismo nombre, aún presentes en la cartografía. Lozano Machuca nos

\footnotetext{
2 Después, con la intensificación de la explotación de las minas de plata durante la Colonia, se transformó en un segundo Potosí, llegando a albergar 15000 almas; hoy subsisten sus ruinas, entre las que se cuentan 30 iglesias o capillas.
} 
informa que esta enorme región, en primer lugar, estaba poblada por 4000 aymaras, lo cual resulta perfectamente aceptable, ya que la toponimia local (actual), es por completo aymara, salvo pocas y dudosas excepciones. Y agrega:

"Demás de estos quatro mill indios, junto al cerro Escala..., hay cuatro pueblos de indios uros, que se llaman Pololo, Notuma, Oromita, Sochusa, questán a cuatro, y cinco, y siete, y diez leguas del cerro Escala, y todos ellos son de SM [es decir, no estaban encomendados], y no dan casi nada de tributo, porque jamás han sido visitados y por tener fama aquella tierra de inhabitable y los indios de pobres".

Demás de los cuatro mill indios referidos, habrá en este repartimiento otros mill indios uros, gente pobre que no siembran ni cojen y se sustentan de caza de guanacos y vicuñas y de pescado y raíces que hay en ciénegas, que llaman coroma; y con estos se hacen pobres los cuatro mill aymaraes, porque siendo gente rica de ganados de la tierra y que cojen y siembran, $y$ tienen contrataciones y rescates en esta villa de Potosí, Tarapacá y Atacama, y que funden muchos metales que sacan de las minas, se excusan de pasar tributo a SM a título de pobres, como los mil indios uros, que lo son verdaderamente.

Estos indios [no está bien claro a cuáles se refiere, aunque parece serlo a los lipes], son extremadamente viciosos de comer coca y tienen de gasto ordinario della cada año más de diez mill pesos ensayados, porque todo el resto que tienen en esta villa de Potosí es llenar coca solamente a su tierra, aunque es gente que no se emborracha, por no ser la tierra dispuesta ni aparejada para dar maíz.

Parece que al tiempo que hizo la visita general el señor D. Francisco de Toledo, no se visitaron ni redujeron estos indios lipes, por tener fama de tierra pobre y cercanos de los de guerra, y porque dos caciques dellos se presentaron ante el señor don F. de Toledo, haciéndole presente de unas plumas de avestruces y unas camisetas de unos animales terrestres que llaman chinchillas [así] y significándole ser gente tan pobre que no alcanzaban sino aquello que le presentaban".

Es sumamente importante que hasta aquí Lozano Machuca nos hable de indígenas uros en una situación geográfica tal, que no sólo comprende el suroeste de Bolivia (cordillera de Lipez con el cerro Escala al norte), sino también parte del extremo noroeste de Argentina que le resulta vecino. Pero aún nos brinda otras importantísimas informaciones:

" $Y$ assimismo dice [Pedro Sande], que hay otros indios que confinan con los indios de guerra de Omaguaca y Casavindo, y tienen trato y comercio con estos lipes, los cuales están neutrales, que no son ni de paz ni de guerra, y entran en Potosí con el nombre de indios lipes y atacamas, con ganados y otras cosas de venta y rescate, y se podrían con facilidad allanar y reducir a nuestra Santa Fe Católica, y sería de mucho provecho, por estar cerca del cerro Escala”.

Hasta aquí, el mosaico étnico que nos permite recomponer la información proporcionada por Sande a Lozano Machuca es la siguiente, según nuestra forma de interpretarla:

1. Hacia la segunda mitad del siglo XVI, el suroeste de Bolivia (actuales provincias de Nor-Lipez y Sur-Lipez), estaba poblarlo por 4000 indígenas aymara. Esta era la población principal, no sólo por su número, sino también por su potencial económico: practicaban un comercio activísimo y era propietaria o al menos explotaba libremente numerosas minas de plata y cobre.

2. Estos aymara no eran antiguos en esa zona, sino que se hallaban en la culminación de un proceso de colonización sobre tribus culturalmente más pobres y de antigua permanencia en la región, llamadas lipes y uros. Este proceso de aymarización prosiguió más tarde con menor intensidad, hasta Jujuy.

3. Más allá de lipes y uros poblaban otros indígenas que limitaban con los de guerra de Omaguaca y Casavindo. Más allá de lipes y uros, que poblaban en las estribaciones de la cordillera de Lipez, significa lisa y llanamente la actual Puna jujeña. Eran pues, los aborígenes de la Puna de Jujuy quienes entraban a la villa de Potosí a comerciar sus productos (rescates) bajo el rótulo de atacamas y lipes. Que realmente hayan sido genuinos lipes o atacamas, no podemos tener la absoluta certeza, pero sí de que culturalmente les hayan sido afines, única circunstancia que les habría posibilitado el cruce de tan dilatadas regiones sin hostilidad alguna. Estos indígenas que comerciaban con Potosí bajo bandera lipe-atacameña (y a los que Lozano Machuca denomina "indios cimarrones que están hacia Omaguaca”), distaban del corazón del 
país de los lipes 25 leguas; eran entonces sus más próximos vecinos, ya que -como expresamente lo aclara- desde los lipes a la propia "tierra de guerra de los omaguacas hay cuarenta leguas". Finalmente, al referirse a los atacamas que poblaban el litoral de Chile, dice:

" $Y$ con estos indios atacamas y cien españoles se podría conquistar toda la tierra de Omaguaca, questá cuarenta leguas de Atacama, y se tratan y tienen rescate entre ellos de oro y plata, y saben toda la tierra, y los omaguacas es poca gente y tienen mucho ganado de la tierra y mucho oro y plata".

En otras palabras, los indígenas atacameños de Chile tenían trato frecuente o continuo con los omaguacas al promediar el siglo XVI, y conocían perfectamente sus tierras; que este tráfico venía de muy atrás en el tiempo, lo prueban las características de la arqueología de la Quebrada de Humahuaca. Y otra comprobación: el hecho de que los atacamas frecuentaran y conocieran la región de Humahuaca, implica obligadamente su pasaje continuo por la Puna jujeña, ya que desde sus cuarteles en los oasis de San Pedro y Toconao, el camino mejor y el más directo pasa por ella, de modo que sus pobladores, o bien pertenecieron o fueron afines a ese grupo, o bien tuvieron que aceptar todo el peso del influjo atacameño que sobre ellos actuó durante tanto tiempo.

Por supuesto, Lozano Machuca deja bien aclarado que el centro principal de los atacamas estaba en Chile, en el valle homónimo, "questá de los lipes cuarenta leguas". Serían, dice, unos 1000 indígenas encomendados a Juan Velázquez Altamirano, vecino de La Plata. Además,

“...en la ensenada de Atacama, que es donde está el puerto, hay cuatrocientos indios pescadores uros, que no son bautizados ni reducidos, ni sirven a nadie, aunque a los caciques de Atacama dan pescado en señal de reconocimiento. Es gente muy bruta, no siembran ni cojen y susténtanse de sólo pescado”.

No debe preocuparnos excesivamente esta insólita aparición de indígenas uros, primero en el cerro Escala, donde los lipes, cerca de Santa Catalina en Argentina, y luego en la costa del Pacífico. En realidad, para el aymara eran tan uros los unos como los otros, es decir, así los lipes como los changos, pues la palabra significa tanto como la frase española "son gente bruta, que no siembran ni cojen". El error, o la confusión, viene de haber llamado uros a los indígenas de la costa del Desaguadero hasta el Titicaca o, mejor dicho, de haberle dado al vocablo un contenido étnico del que careció. Así figuran aquellos en todos los mapas étnicos, así han entrado a la literatura etnográfica de mayor predicamento, y difícilmente haya quien esté dispuesto a sacrificarla, a pesar de estar bien claro que los uros del Desaguadero se llamaban oshomazos (gente del agua). Donde quiera que veamos la palabra, que está muy difundida -uru, uro, uruquilla, urinsaya, etc.-, podemos tener la seguridad de que ha sido aplicada por el aymara a un pueblo recolector y primitivo.

Muy poco más se puede decir en torno a las características étnicas de los pueblos existentes en la región inmediatamente después de la conquista española; por supuesto, mucho más debe existir en fuentes inéditas, pero este aspecto está aún completamente descuidado. La arqueología de todo ello, ya lo dijimos, es pésimamente conocida. Lo poco que sabemos, lo debemos a Ibarra Grasso (1944, 1952, 1965, 1967). Lo que hemos podido afirmar en base a los escasos datos proporcionados por la crónica histórica, no siempre lo podremos sostener por medio de su fundamentación arqueológica. Comenzando desde el norte, en contacto con los chichas, en primer lugar deberemos citar a lo que Ibarra Grasso denomina cultura Yura, del centro de Potosí, con sus característicos vasos campanuliformes (Figura 2e, f), así como la Huruquilla del centro-este del mismo departamento boliviano. Deberemos tener muy presentes los tipos de cerámica que ambas ofrecen, porque vuelven a presentarse en lugares muy distantes y sin aparente vinculación cultural: por ejemplo, el vaso con asas verticales de la Figura 2a. procede de Calama (Chile) (Boman 1908: Fig. 181), mientras que el de la Figura 2c procede de su centro de origen, el valle de Cagua (Yura, provincia de Porco, Bolivia). El espécimen de la Figura 2b, en cambio, es oriundo de Pueblo Viejo, en la quebrada de Tucute, y el de la Figura 2d de Taranta, cerca de Casabindo (Bregante 1926: 178-179), sitios arqueológicos ambos de la Puna de Jujuy. No será extraño que esta cerámica tan particular vuelva a presentarse en territorios del norte de Chile y Argentina. Tanto el tipo Huruquilla como el Yura están indudablemente emparentados, siendo posible que finalmente resulten pertenecer a distintas etapas de una misma cultura; pero cómo pudieron mantenerse en forma tan pura, al punto de resultar relativamente sencillo determinar su procedencia, a tanta distancia de su presunto centro de origen en Bolivia, resulta inexplicable si no se recurre a la posibilidad de que haya sido un producto de intercambio. 

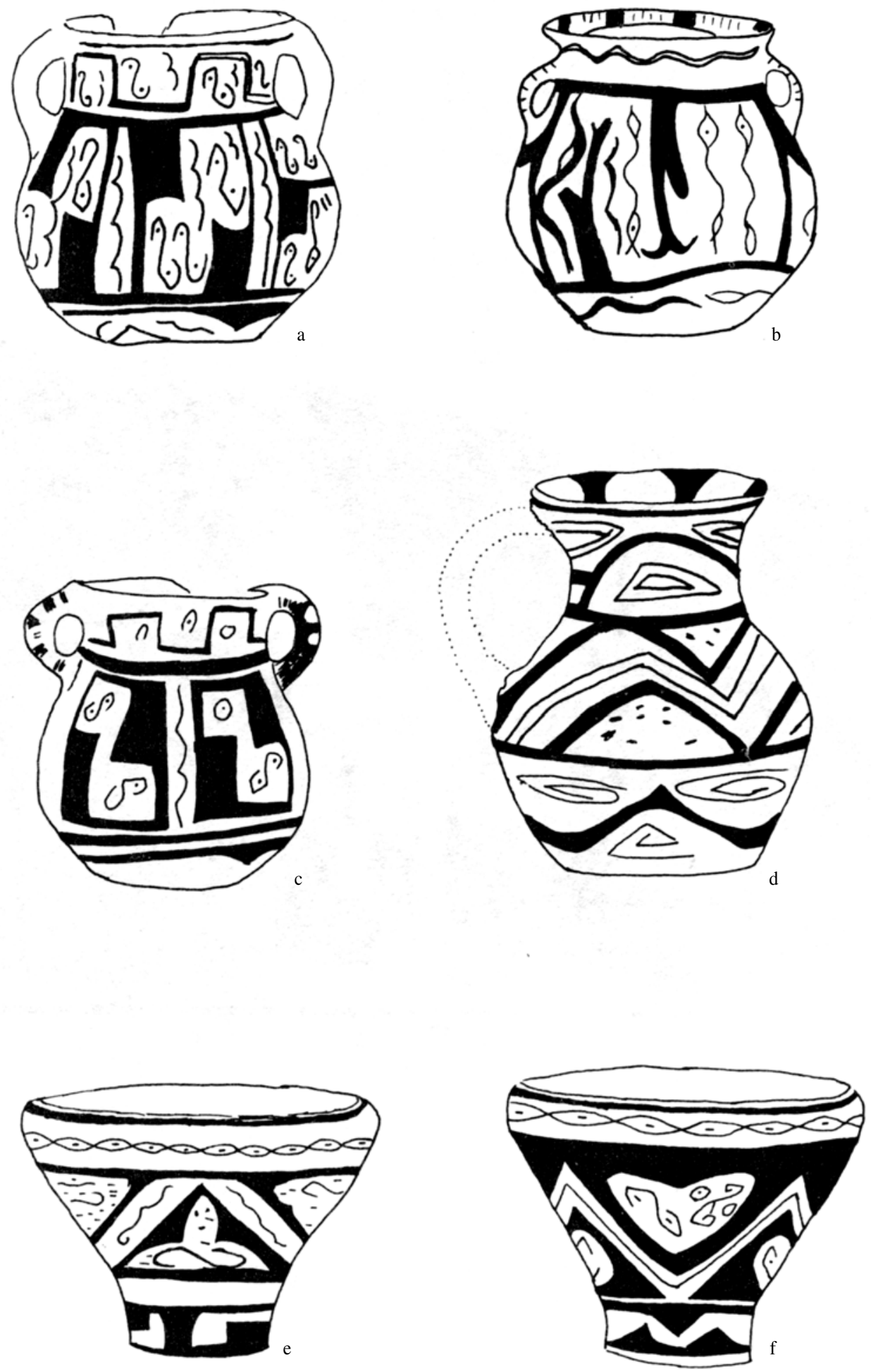

Figura 2. Cerámica Yura y Huruquilla. 
Pero carecemos de una explicación igualmente sencilla para la cerámica corrugada de tipo imbricado que aquí y allá hace su aparición en la región andina. Se trata de una tosca cerámica rojiza (Figura 3), que a veces se presenta negra a causa de su prolongada permanencia en contacto con el fuego. El antiplástico es siempre muy grueso. No conocemos piezas enteras, solamente fragmentos, los que por primera vez se presentaron $40 \mathrm{~km}$ al oeste de Humahuaca, y luego en El Toro, departamento de Susques, Jujuy, sobre la frontera con Chile, y que hasta ahora no pudimos publicar (Fernández 1976). Ignoramos si los hallazgos de Gatto (1946: 56), confirmados posteriormente por Suetta (1969: 6), así como los de Cigliano (1970: 102) en Salta, constituyen una identidad con la nuestra. Pero, en cambio, es idéntica a la hallada por Le Paige (1964, Fig. 2) en el yacimiento único de Poconche. No sabemos aún qué significación pueden tener estos restos. Durante 1976 hemos permanecido durante un mes en la región boscosa de San Francisco y Santa Bárbara -ambos, centros arqueológicos donde está muy difundida la cerámica imbricada, corrugada, etc.- con el propósito de rastrear allí presuntas vinculaciones; sólo podemos expresar por ahora que lo que se presenta en la región montañosa occidental aparenta ser algo enteramente distinto.

Tampoco es fácil dar una explicación satisfactoria a la presentación en el límite argentino-boliviano, de una cerámica gris, con escaso pulimento y decoración incisa, de apariencia bastante tosca (Figura 4a), en su mayoría vasos cilíndricos de bordes evertidos, de pequeño tamaño. No sabemos qué clase de relación puede guardar con otra cerármica que también aparece allí, la que ofrece figuras zoomorfas modeladas aplicadas a las asas (Figura 4b). Ibarra Grasso cita la cerámica Tarija inciso y Lipes inciso, pero la carencia de ilustraciones en sus trabajos impide todo intento de comparación.

Los materiales obtenidos en Calahoyo, tambo incaico que las crónicas dan como asiento de pueblos chichas, nos parecen sumamente importantes. No proceden de una excavación científicamente encarada, pero sería necio por este solo motivo invalidar el potencial informativo existente en este yacimiento, en el que he estado ya tres veces, al que conozco perfectamente y donde he presenciado la exhumación de buena parte de los materiales a que aludo, en cuya venta

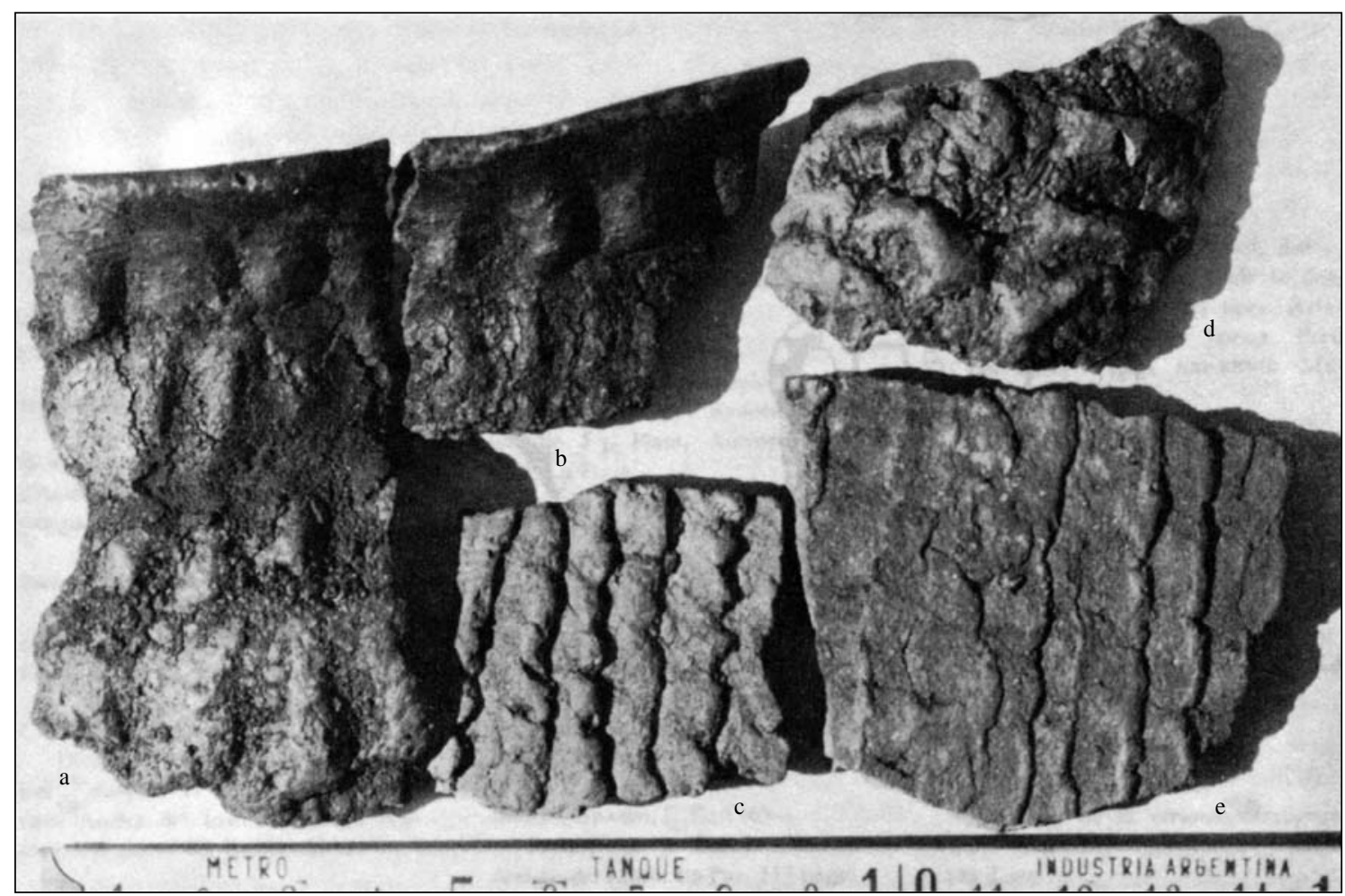

Figura 3. Cerámica corrugada de tipo imbricado. Los fragmentos a y h proceden de El Toro en la frontera chileno-argentina; los fragmentos c, d y e proceden de Cristóbal, a $40 \mathrm{~km}$ al oeste de Humahuaca y $3500 \mathrm{~m} . \mathrm{smm}$. 


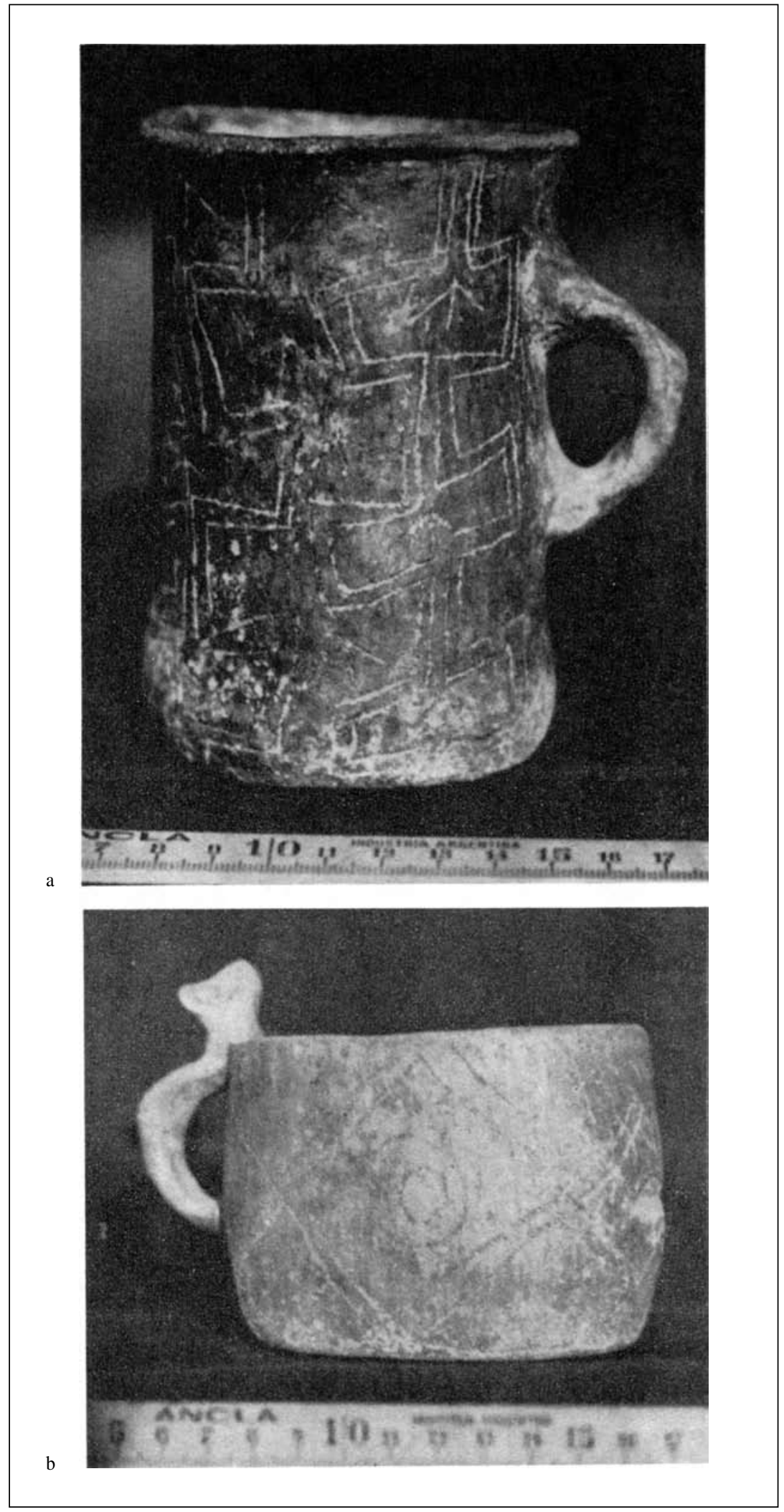

Figura 4. Cerámica gris incisa, procedente de Calahoyo, Sur Chichas, Bolivia. 
la población local halla un recurso para procurarse la existencia.

En primer lugar, nos encontramos con grandes cantidades de cerámica utilitaria, cuyo empleo se prolonga hasta la actualidad, pues varios de los vecinos de Calahoyo son olleros de profesión. En superficie, se observan fragmentos no muy frecuentes de cerámica incaica y de algunos tipos cerámicos característicos de la Quebrada de Humahuaca. Nuevamente nos encontramos en la disyuntiva de que o aceptamos que se trata de un producto de intercambio, o admitimos que en algún momento la cultura de la quebrada se extendió hasta ese punto.

Una cosa curiosa es que entre los elementos de excavación no se encuentra cerámica incaica en la proporción que permitiría sospechar su carácter de tambo incaico que todos le han reconocido a este sitio. Lo que allí predominan son unos vasos simples con asa, cilíndricos y troncocónicos, asa simple o doble. Externamente están bien alisados; cuando la tienen, su decoración consiste en motivos lineales simples, trazos finos con pintura negra en forma de enrejados, otras veces adoptando la forma de un tablero de ajedrez, aplicada sobre el fondo bayorojizo de la cerámica. Ibarra Grasso (com. pers.) asigna esta cerámica al tipo chicha o chichoide, pareciendo ser su dispersión mayor hacia el interior de Bolivia, aunque no existen estudios al respecto (Figuras 5, 6 y 7). Se presenta en Calahoyo, donde predomina, asociada a gran cantidad de punzones de cobre, cuentas de collar de sodalita, palas de piedra, pequeños morterillos de piedra negra esquistosa muy pulida y pequeñísimas puntas de proyectil pedunculadas. Según comunicación personal de George Serracino, que mucho agradezco, esta cerámica habría también hecho su aparición en los oasis de Atacama, existiendo algunos ejemplares en el Museo Arqueológico de San Pedro, hallados anteriormente por Le Paige. Los que publicamos ahora, son los primeros ejemplares de la cerámica de los chichas, cuya existencia en Argentina fue motivo de tantas $\mathrm{y}$ tan agrias disputas.

Otro elemento que inesperadamente se ha presentado en dos puntos de la zona fronteriza argentinoboliviana, primeramente en el ya aludido Calahoyo y últimamente en Casira, en el departamento jujeño de Santa Catalina, es una cerámica caracterizada por su tamaño relativamente pequeño, extremada delgadez de sus paredes y notable pulimento de sus superficies exteriores. En su mayoría se trata de vasijas de formas restringidas, mayormente botellones de cuerpo ovoide, cuello cilíndrico de paredes convexas, en algunos casos con aplicaciones antropomorfas (Figuras 8 y 9); vasijas triesferoides (Figura 10), vasos de forma cilíndrica y subcilíndrica (Figuras 11, 12 y 13), vasos podos grandes (Figura 14), los cuales corresponden casi exactamente a tipos ilustrados por Le Paige (1964), como tipos característicos y representativos del tipo San Pedro Negro Pulido, que tiene su centro de dispersión en la región de oasis de San Pedro de Atacama. Sin embargo, opina George Serracino que ciertos detalles de forma y decoración, no son conocidos en algunos casos, y en otros no son frecuentes en San Pedro. Si esta circunstancia pudiera comprobarse fehacientemente, existiría un buen argumento para el replanteo de las posibilidades referentes a si se trata de un producto del comercio aborigen, o si en cierta etapa de su desenvolvimiento cultural, Calahoyo ha albergado algo así como una especie de colonia o establecimiento atacameño; esto llevaría el inicio de las relaciones al Período Medio, y aun podría alcanzar el Temprano.

Con todo lo que hemos expuesto, no hemos solucionado absolutamente nada; ni siquiera pretendemos haber planteado un interrogante. Sí afirmamos, en cambio, que la totalidad de estos materiales arqueológicos, en su conjunto, vienen a llamarnos la atención sobre la urgencia de iniciar estudios en estas zonas de Argentina y Bolivia, de manera especial por la necesidad de unificar en alguna medida los respectivos desarrollos culturales. Ciertamente, en su mayoría, estos restos que hemos examinado parecen corresponder a pequeñas culturas locales evolucionadas no muy independientemente en una enorme región marginal -tal es el caso de Yura y Huruquilla-, pero otras, como la de San Pedro, parecen haber alcanzado en ciertos momentos un potencial de irradiación que en algunos aspectos va mucho más allá de lo que inicialmente podría haberse supuesto. No olvidemos que los clásicos botellones con aplicaciones antropomorfas del tipo San Pedro Negro Pulido, ya con anterioridad se han presentado en los valles calchaquíes, en $\mathrm{La}$ Paya de Cachi y en La Paya del valle de la Poma. En el presente caso de Calahoyo y Casira, donde ahora vuelve a presentarse esta cerámica negra y lustrosa, es posible recurrir al intercambio como explicación, pero también se abren a la investigación otras posibilidades. La información etnohistórica con que contamos, por lo menos, refleja con claridad la función dominante, aun con claros aspectos 

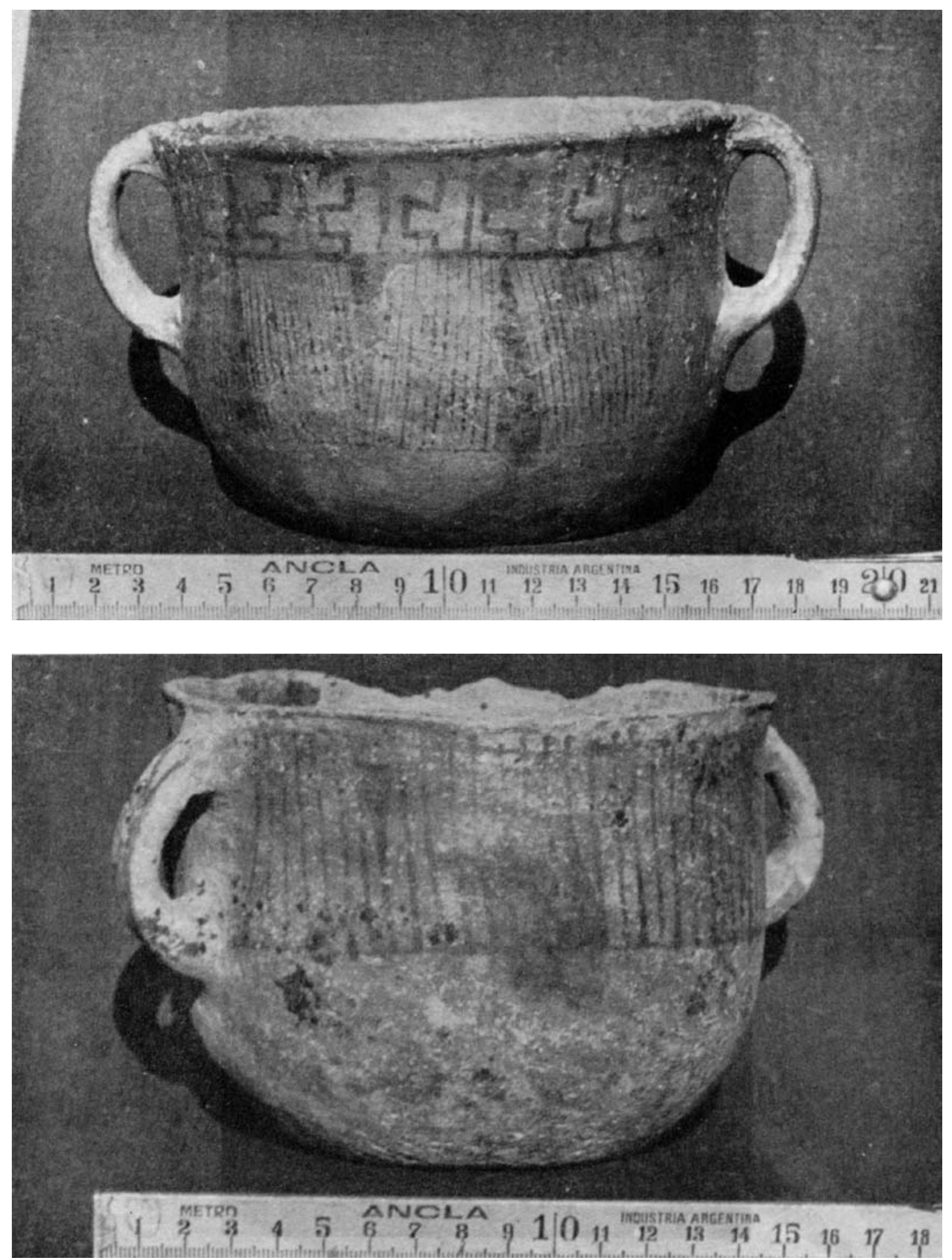

Figura 5. Cerámica chicha o chichoide. 

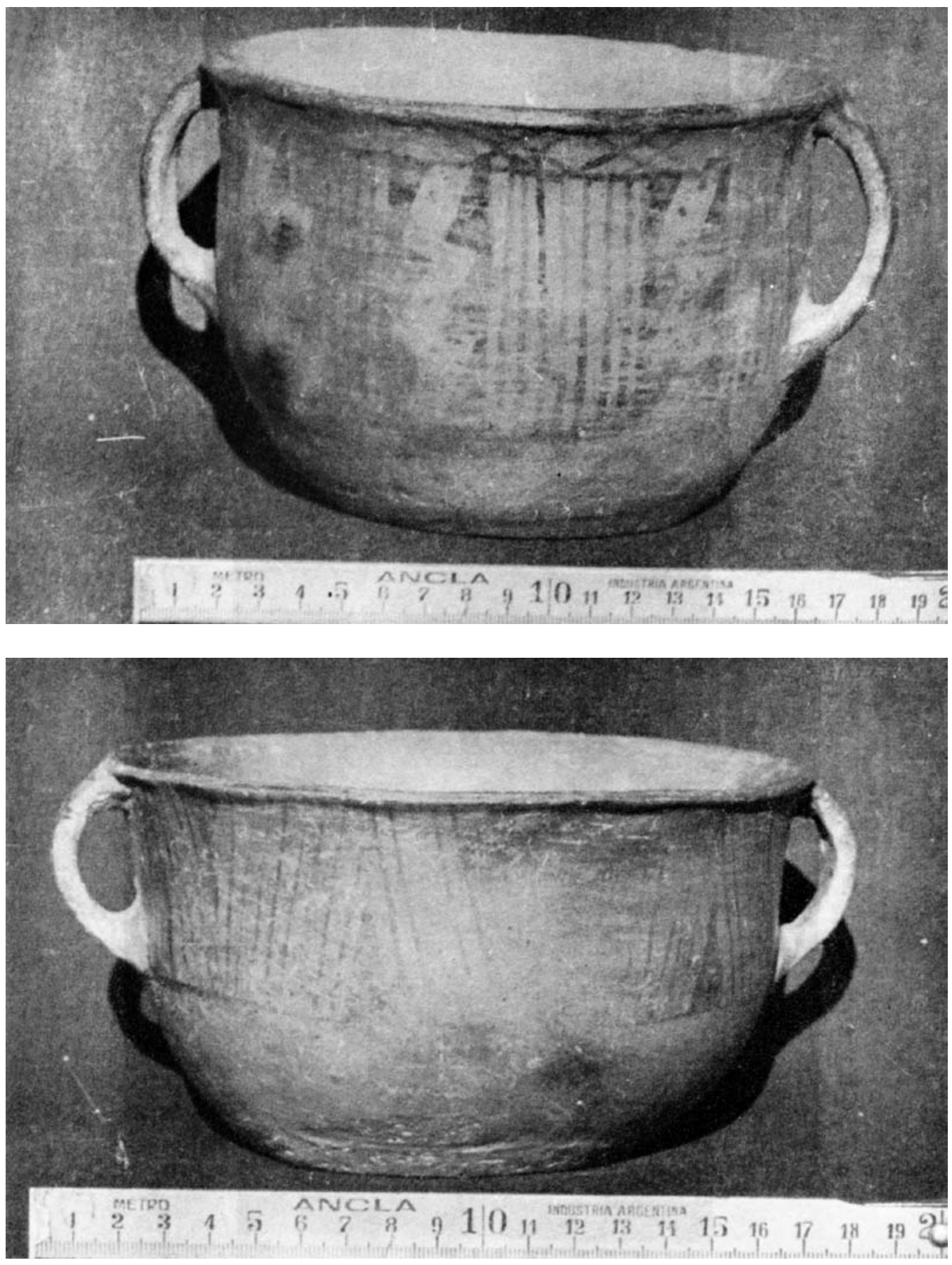

Figura 6. Cerámica chicha o chichoide. 


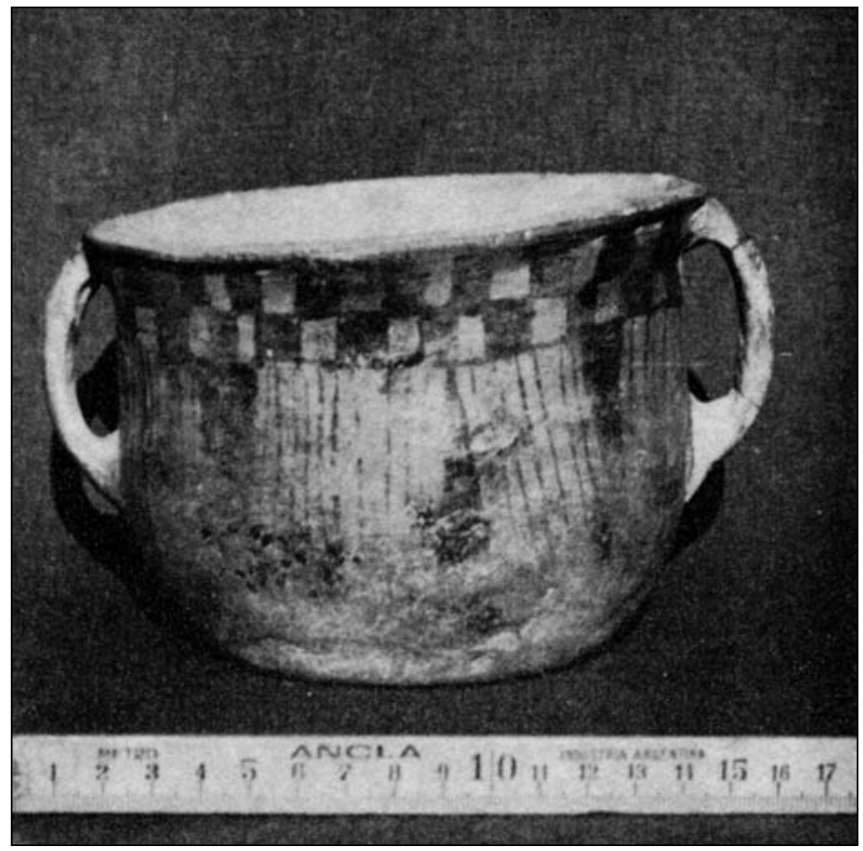

Figura 7. Cerámica chicha o chichoide.

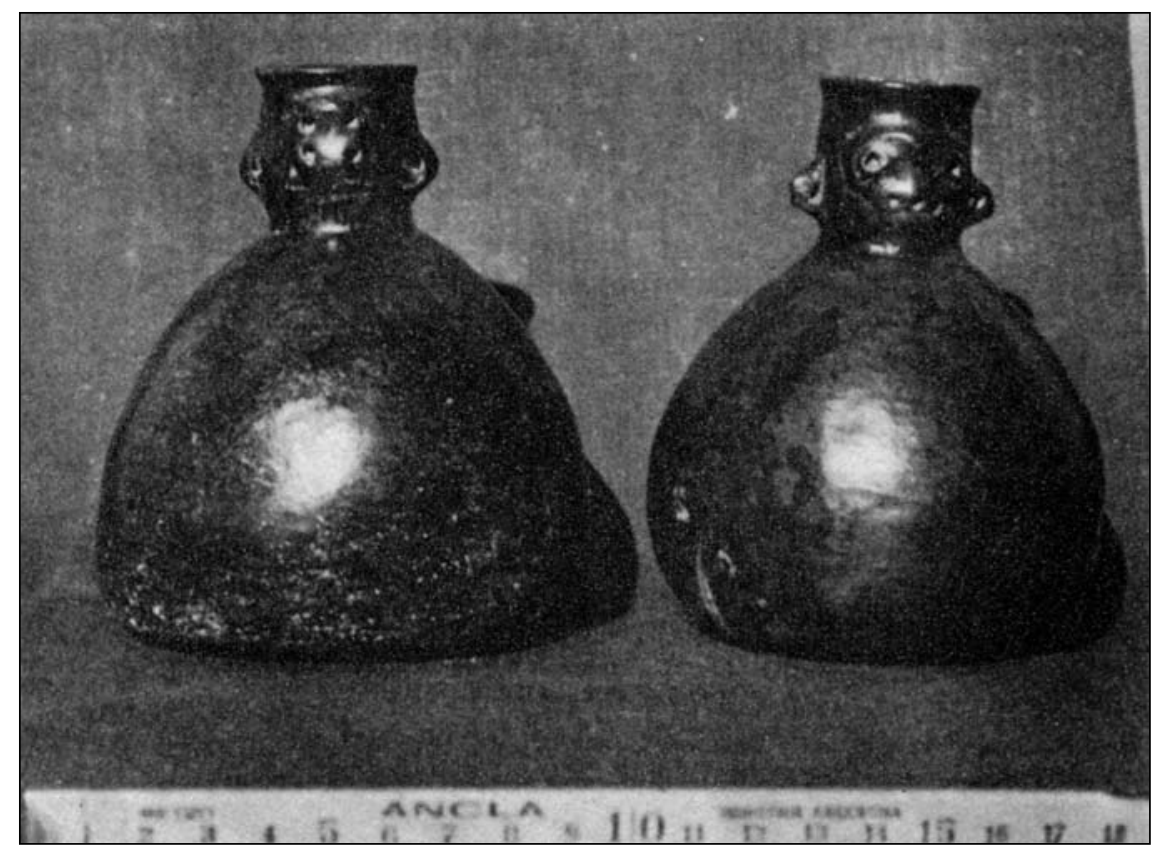

Figura 8. Vasijas restringidas negras pulidas de paredes delgadas 


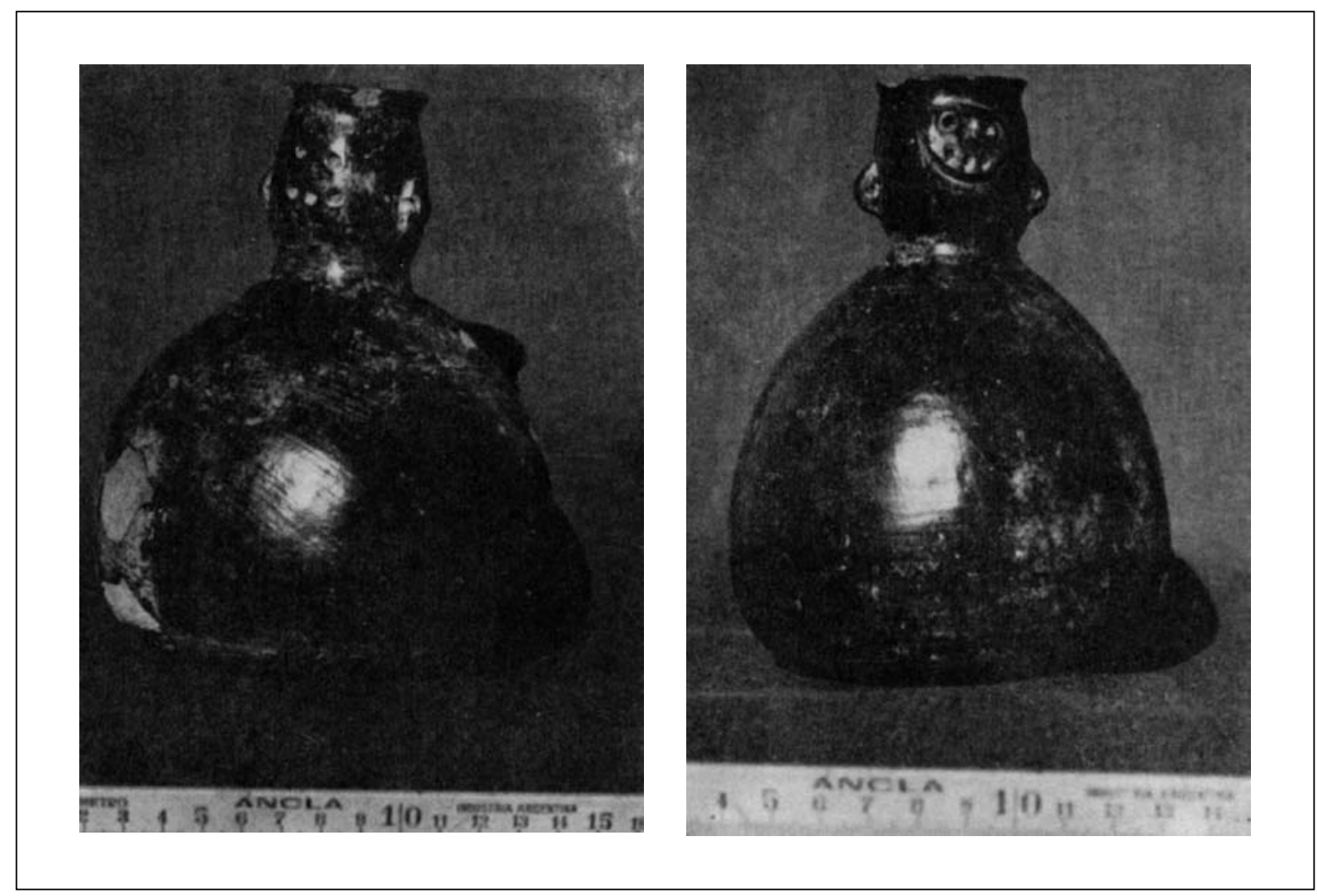

Figura 9. Vasijas restringidas negras pulidas de paredes delgadas

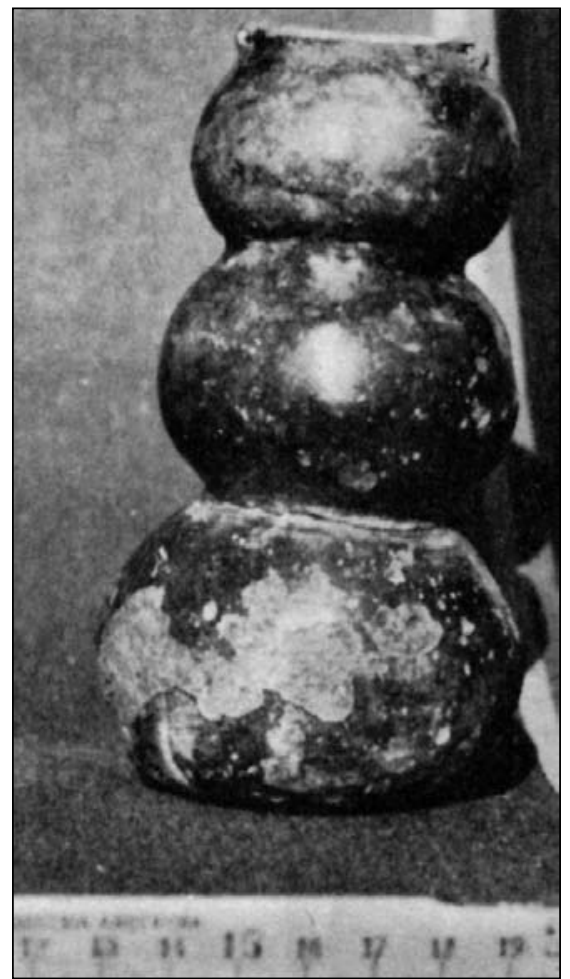

Figura 10. Vasija triesferoide.

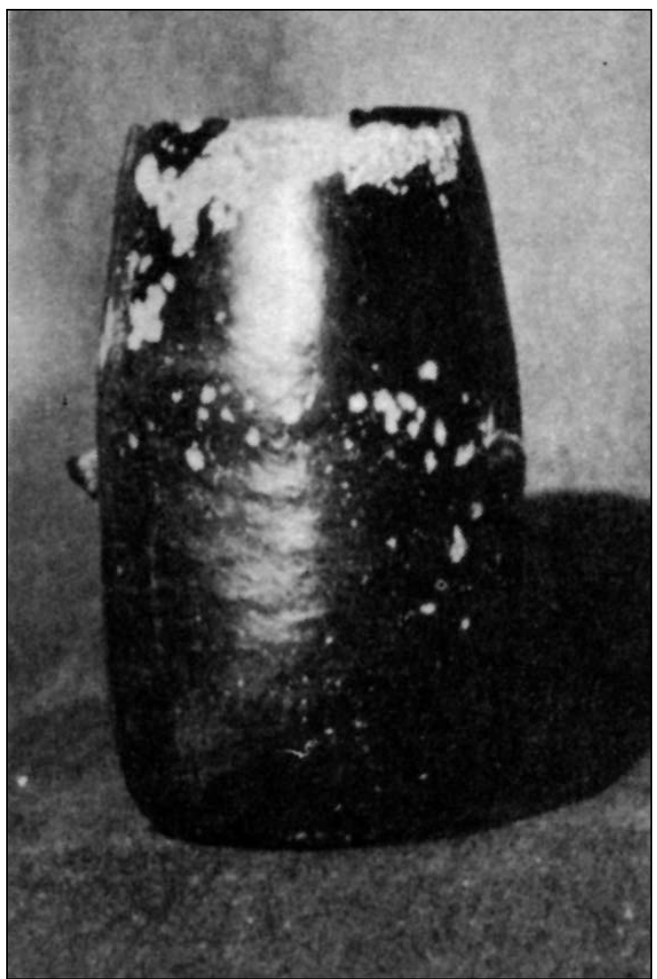

Figura 11. Vaso cilíndrico. 


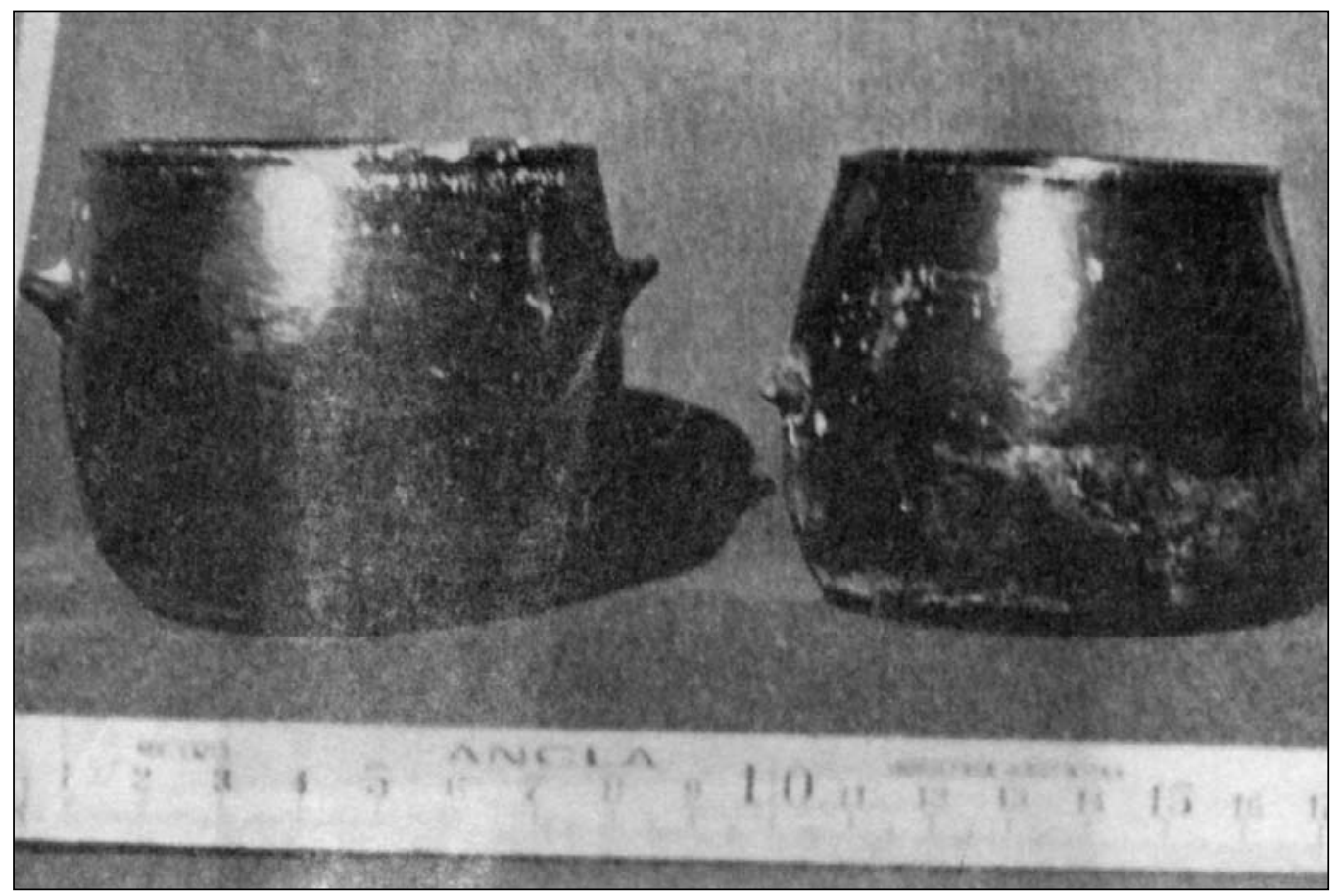

Figura 12. Vasijas cilíndricas.

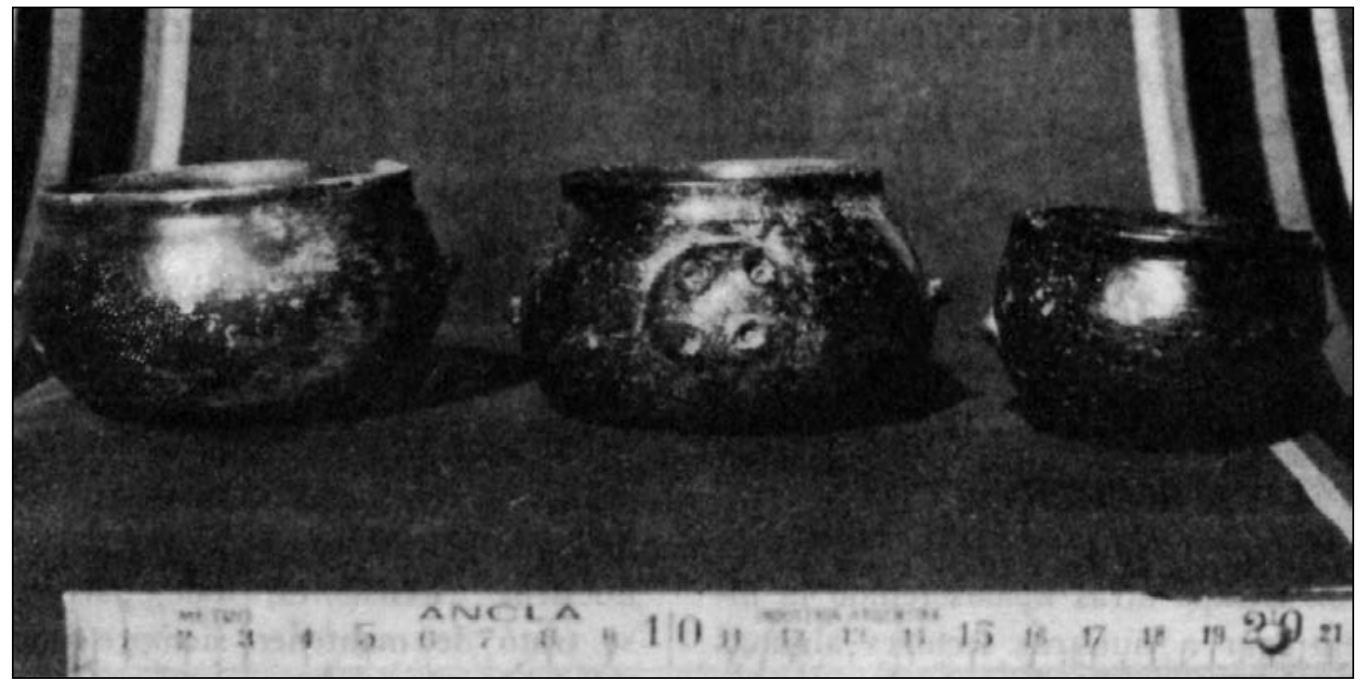

Figura 13. Vasijas subcilíndricas.

hegemónicos, ejercida sobre los pueblos vecinos por la cultura emanante de San Pedro.

De todos modos, estas asociaciones al parecer caóticas y un tanto desconcertantes por los aspectos problemáticos que entrañan, deben ser valoradas y miradas en su justa medida, porque el desconcierto es más bien un producto de nuestra falta de conocimientos al respecto. En el caso del occidente jujeño, por lo menos, es evidente que la influencia -si no la presencia física o el poblamiento directo-, procedente de Atacama no sólo ha estado limitada a los momentos tardíos y protohistóricos -como ya lo anticipara Boman en su esquema étnico de 1908-, sino que se habría iniciado ya en el Período Medio $y$ aun en el Temprano. 


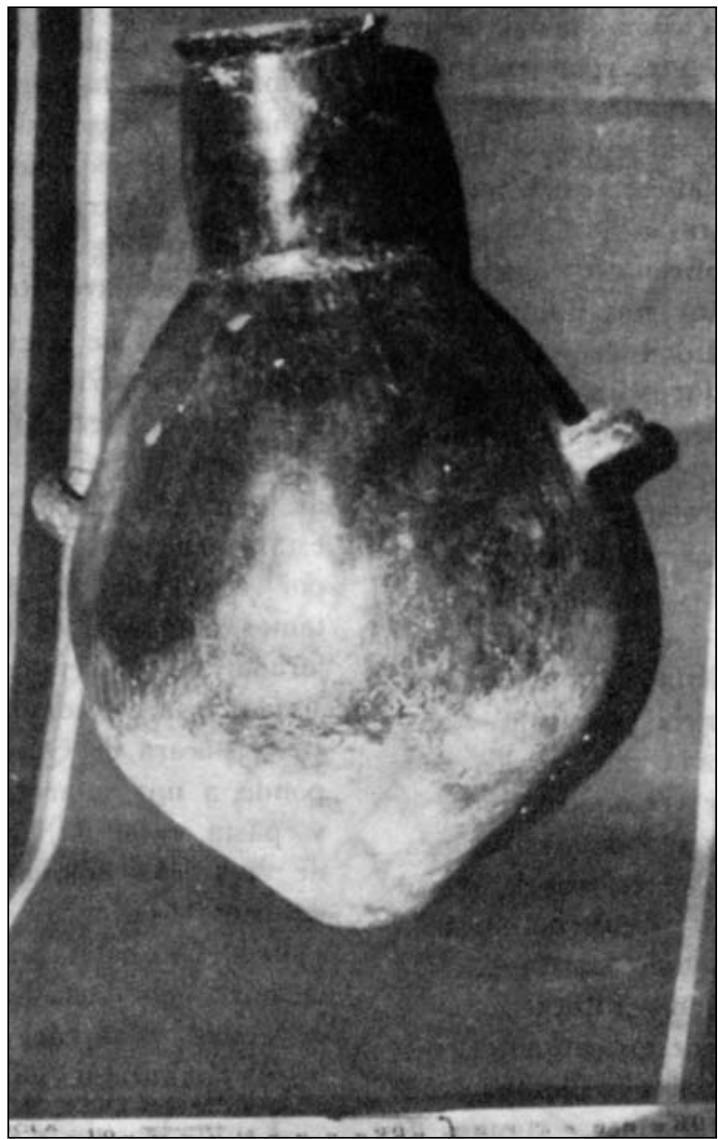

Figura 14. Vasija base apuntada.

\section{REFERENCIAS CITADAS}

BENNETT, W., BLEILER y SOMMER, 1948. Northwestern Argentine archaeology. Yale University Publications in Anthropology, 38-39: 13-157, New Haven.

BOMAN, E., 1908. Antiquités de la región andine de la Republique Argentine et du déssert d'Atacama. Imprimerie Nationale, París.

BREGANTE, O., 1926. Ensayo de clasificación de la cerámica del Noroeste Argentino. Editorial Estrada, Buenos Aires.

CANALS FRAU, S., 1951. División y unidad en las poblaciones prehispánicas del Noroeste Argentino. Anales del Instituto Etnico Nacional IV (2): 67-88.

— 1953. Las poblaciones indígenas de Argentina. Su origen, su pasado, su presente. Editorial Sudamericana, Buenos Aires.

FERNANDEZ, J. 1976. Arqueología de la cueva de El Toro, departamento de Susques, Jujuy. Relaciones de la Sociedad Argentina de Antropología X: 43-65.
1977 Ms. Contribución a la arqueología de Calahoyo, Sud Chichas, Bolivia.

GATTO, S. 1946. Exploraciones arqueológicas en el Pucara de Volcán. Revista del Museo de La Plata, Antropología IV: 5-91.

IBARRA GRASSO D. E., 1952. La arqueología boliviana. Ciencia Nueva I (4): 7-20.

_ 1944. Las ruinas y la cultura de los yuras. Revista Geográfica Americana 127.

— 1965. Prehistoria de Bolivia. Editorial Los Amigos del Libro, La Paz.

— 1967. Argentina indígena. Prehistoria americana. Editorial Tea, Buenos Aires.

LE PAIGE, G., 1964. El precerámico en la cordillera atacameña y los cementerios del Período Agroalfarero de San Pedro de Atacama. Anales de la Universidad del Norte 3: 1-275. 
LOZANO MACHUCA, J., 1885. Carta del factor de Potosí, don... al Virrey del Perú, en donde se describe la provincia de los lipes. Relaciones Geográficas de Indias, Perú II, apéndice 3, pp. XXI-XXVIII, Madrid.

RIVET, P., 1924. Langues americaines. En Langues du monde, París.

SERRANO, A., 1947. Los aborígenes argentinos. Editorial Nova, Buenos Aires.
— 1966. Manual de la cerámica indígena. Editorial Assandri, Córdoba.

SUETTA, J. M., 1931. Aportes a la arqueología de Volcán, provincia de Jujuy. Antiquitas 8: 1-6.

VIGNATI, M. A., 1931. Los elementos étnicos del Noroeste Argentino. Notas Preliminares del Museo de La Plata 1: $115-117$. 